\title{
Nanometer-scale imaging of organic matter composition within the Eagle Ford Shale (Texas, United States) using atomic force microscopy-based infrared spectroscopy
}

\author{
AARON M. JUBB ${ }^{1}$, PAUL C. HACKLEY ${ }^{2}$, JUSTIN E.
} BIRDWELL $^{2}$ AND JING QU ${ }^{3}$

\author{
${ }^{1}$ U.S. Geological Survey \\ ${ }^{2}$ US Geological Survey \\ ${ }^{3}$ University of Delaware \\ Presenting Author: ajubb@usgs.gov
}

The nanoscale molecular composition of sedimentary organic matter $(\mathrm{OM})$ provides insight into important reservoir parameters such as thermal maturity, fluid movement, mineral associations, and depositional conditions. In unconventional (i.e., shale or source-rock) petroliferous reservoirs, where multiple OM types may be present in intimate contact with surrounding mineral phases, OM compositional data is especially useful for informing structure-reactivity relationships relevant to understanding petroleum generation. However, the molecular makeup of shale $\mathrm{OM}$ is difficult to investigate in situ given its complexity and the small $(<1 \mu \mathrm{m}$ to $\sim 100 \mu \mathrm{m})$ OM grain sizes typically present. The recent advent and application of atomic force microscopy-based infrared spectroscopy (AFM-IR) to geologic materials overcome these analytical obstacles, facilitating direct examination of major compositional features at the individual OM particle-scale within the rock matrix. AFM-IR can achieve spatial resolutions of or below $50 \mathrm{~nm}$, orders of magnitude finer than is possible with conventional micro-spectroscopic approaches.

Here we present the results of an investigation using AFM-IR to examine inertinite, preserved terrestrial plant material that was charred or oxidized prior to deposition, present in a thermally immature Eagle Ford calcareous mudstone collected from south Texas, United States. The application of AFM-IR allows for rapid two-dimensional imaging of the distribution of major $\mathrm{OM}$ molecular groups (e.g., $\mathrm{C}=\mathrm{C}, \mathrm{CH}_{2}$, and $\mathrm{C}=\mathrm{O}$ moieties) across 160 $\mu \mathrm{m}^{2}$ fields-of-view at spatial resolutions of $\sim 100 \mathrm{~nm}$ such that each image comprises $>100,000$ individual compositional data points. We contrast the inertinite data with AFM-IR observations from solid bitumen present in Eagle Ford samples at higher thermal maturity stages and with literature data from inertinite present in another U.S. unconventional petroleum system, the New Albany Shale. Our results show that the nanoscale molecular composition of Eagle Ford inertinite is (i) more homogenous than Eagle Ford solid bitumen and (ii) more hydrogen- and oxygen-rich than inertinite examined in the New Albany Shale. These findings highlight striking differences in molecular structure between OM types from the same geologic formation and suggest that inertinite in the Eagle Ford experienced less charring/oxidation prior to deposition than inertinite from the New Albany Shale. 